\title{
EDUCATIONAL
}

TECHNOLOGY

\section{Telephones, teaching and technical trickery}

\author{
Project Brief
}

\author{
Graham Anderson \\ Education Officer \\ Educational Technology Unit \\ Northern Territory Department of Education
}

Telephone lessons and telephone conferences are no longer at the experimental stage. Teaching programs of varying degrees of length and complexity have been conducted through telephones all over Australia in the past decade. One of the leaders in the field of classroom telephones, the 'DUCT' equipment developed in South Australia, is now being mass produced, and marketed nationally with the help of Hanimex and Telecom.

Reports emanating from southern states indicate a high level of satisfaction with the DUCT as an educational communications tool, but the Northern Territory experience is different. Here, two factors mitigate against its success: the quality of the communications network and the geographical distribution of the population. Both of these factors interact in an unsatisfactory way with an inherent feature of DUCT, called voice activated switching or voice-switching.

Some terminology needs to be clarified here. The generic term 'Loudspeaker Telephone' refers equally to small desktop units, suitable for small groups to gather around, and other units suitable for much larger groups of people to participate in a telephone conversation, conference, or lecture. The latter type is the subject of this article, and is referred to as a Classroom Loudspeaker Telephone. DUCT, and the Northern Territory designed 'Classphone' described later, are two examples of Classroom Loudspeaker Telephones. 


\section{Voice-switching in loudspeaker telephones}

With the DUCT, and almost all commercially available loudspeaker telephones, conversation can only take place in one direction at a time like cars crossing a one-lane bridge. When one person finishes speaking and the other starts, the equipment detects and second voice, and switches the second machine to 'speak', the first to 'listen'. It changes back again when the first speaker responds again. The electronic switch alternates as the speakers alternate. They can not normally speak simultaneously, and they can not hear the other party while speaking themselves. As a rule this is no problem, with good telephone lines and confident, articulate participants. Even if the telephone lines are slightly noisy, so long as the background noise is continuous and uniform, the DUCT voice-switch can be fine-tuned to respond rapidly to alternating speakers, with hardly any perceptible delay or loss of syllables or words. Unfortunately, in the Northern Territory, telephone line noise tends to be neither continuous nor uniform, and the DUCT equipment does not perform well.

\section{Communications conditions in the Territory}

Isolated Northern Territory communities, those that have telephones, are generally not connected directly to high-grade microwave links. Their telephones are linked to the network through a tropospheric-scatter system or UHF radio links. The former system is affected by the daily cycle of changes in the upper atmosphere, the latter by wind and dust and both by lightning, clouds and rain. The telephone links are often noisy, and incoming voices are faint. In these conditions it is impossible to adjust a DUCT classroom telephone to respond quickly to alternating speakers. Sometimes it will not respond at all, and no communication can take place. Such conditions give no encouragement to a teacher ready to conduct a telephone lesson, nor to the students who were to take the lesson. If the students are shy or unsure, they tend to respond to the teacher's questions and prompts in monosyllables, which are lost in the delay of the voiceswitch. If they are using English as a second language as applies in most Northern Territory isolated communities, the tendency to answer in monosyllables is even greater. In these conditions the DUCT ceases to be a useful tool. Even if the teacher is enthusiastic, well-prepared, and on good familiar terms with the students, the poor quality of communications, aggravated by the voice-switch, represents an obstacle rather than an aid to effective educational communication.

\section{Our alternative}

Since August 1985, the Northern Territory Secondary Correspondence School has been conducting a regular program of lessons in Maths and English by telephone with post-primary students in the Aboriginal 
community of Oenpelli. Each Wednesday, a group of five students attend a half-hour lesson in each subject, and another group of eight do the same on Thursdays, using equipment loaned to the Oenpelli School by the Educational Technology Unit of the Northern Territory Department of Education. The fact that the lessons are proving successful on a long-term basis appears due to two factors - the enthusiasm and dedication of the teachers involved (Peter Allery, Marion Watson, June Lewis, Sue Dodd and Jill Billyeald of the NTSCS), and the effective performance of the experimental telephone equipment under trial.

The essential feature of the classroom telephone being used at Oenpelli is that there is no voice-switch. The teacher in Darwin can hear the students continually. Brief answers by the students can be heard clearly, as well as murmurs of puzzlement, discussions between the students, their comments, and their reactions to the teacher's instructions, jokes, questions, and so on. Similarly, the students continue to hear the teacher even when they have a high level of environmental noise, such as when trucks pass by close to the school. Quite apart from ambient noise, the level of noise occasionally heard on the telephone line is enough to render any voice-switched telephone inoperative. Apparently, the human ear is able to be much more selective than an electronic switch, and to distinguish speech and other sounds against a reasonably high level of background noise.

Readers familiar with Loudspeaker Telephones may be wondering how full-duplex (continuous two-way) communication has been achieved for the Oenpelli lessons. The voice-switching in Loudspeaker Telephones is normally an essential part of their design, so as to avoid acoustic feedback ('squealing') from the loudspeaker to the local microphone. The voiceswitching is not essential, however, if there is no loudspeaker; if, for example, the sound is directed instead to headphones. The introduction of headphones might itself create unacceptable problems. The students would need to be clustered around a listening post or other distribution point near the telephone; and their movements would be restricted to the length of their headphone cables. The solution we adopted to these problems was the use of cordless headphones. These allow the students individual freedom of movement, as well as not requiring them to be closely clustered around one point, although they must still be reasonably close to a microphone. The equipment currently in use is a somewhat untidy combination of devices, as it is still an experimental concept (see below), but a prototype unit including all the essential elements in one neat box has been completed and is undergoing a series of trials. 
The components in use in the classroom at Oenpelli at present include:

- A modified loudspeaker telephone, with an external speaker output (to the cordless head- phone transmitter), an external microphone input (from the microphone mixer), and a switch to eliminate the voice switching when desired

- A microphone mixer with four microphone input sockets

- Four microphones, shared between the students

- An infra-red headphone transmitter and its plug-pack power supply

- One infra-red headphone per student

- A facsimile machine as a separate unit, to allow the transmission of printed material between the teacher and the students.

It would be overstating the case to say that the present arrangement of equipment solves all the technical problems of telephone teaching. although it is proving to be very satisfactory. The use of infra-red headphones was expedient for the purpose of trialing cordless headphones in this application: they are portable, with only low input amplification and little installation effort required. But they also require the students to face the infra-red transmitter, such that they cannot turn their heads through more than 180 degrees without losing the transmitted sound. In order to solve this problem, the new self-contained prototype contains an amplifier, which will permit the use of induction-loop cordless headphones. The induction loop needs to be made a more permanent installation, but this type of headphone will allow more freedom of movement to the students than the infra-red type.

\section{The Northern Territory prototype 'classphone'}

The prototype classroom telephone developed by the Northern Territory Educational Technology Unit is of similar dimensions to the DUCT, but contains more features. It requires no telephone attachment - the telephone, including dial pad, is built in. It has six microphone inputs, an output for an extension loudspeaker and another for headphones, which accepts a listening post or connection to a cordless headphone transmitter. There is an automatic changeover, such that voice-switching is normally not in effect when using headphones, but it is if using a loudspeaker. Power supply to the unit is $123 \mathrm{~V} \mathrm{DC}$, supplied from a plugpack, which drives the output amplifier and the fail-safe relay. If the town powersupply fails, the unit reverts to functioning as a small loudspeaker telephone, dependent only on the telephone line voltage, so that communication is not immediately lost. All inputs and outputs are on the rear panel. On the front panel there is a volume control, a power On/Off switch and a Call-Answer/Hang up switch. The number of persons who 
can use the unit is limited mainly by the six microphones, though eighteen persons at three per microphone should be more than sufficient. There can be any number of observers using infra-red, induction loop, or FM radio cordless headphones.

Further inquiries should be directed to Mr Graham Anderson, Education

Officer, Educational Technology Unit, Department of Education, PMB 25,

Winnellie, NT 5789.

Please cite as: Anderson, G. (1986). Telephones, teaching and technical trickery. Australian Journal of Educational Technology, 2(2), 123-127.

http: / / www.ascilite.org.au/ajet/ajet2/anderson.html 